\title{
Rhabdomyosarcoma of the cervix uteri
}

INSERM

\section{Source}

INSERM. (1999). Orphanet: an online rare disease and orphan drug data base.

Rhabdomyosarcoma of the cervix uteri. ORPHA:213802

Rhabdomyosarcoma of the cervix uteri is a rare, highly malignant soft tissue sarcoma located in the uterine cervix and arising from primitive mesenchymal cells displaying skeletal muscle differentiation. It most often presents with abnormal vag inal discharge or dysfunctional uterine bleeding, abdominal pain and/or a cervical mass protruding into the vagina. Association with DICER1 syndrome has been reported. 